\title{
Managing Pensions Obligations in Volatile and Demanding Environments: A U.K. Perspective
}

\author{
Richard Harvey \\ Aviva plc, St. Helen's, 1 Undershaft, London EC3P 3DQ, U.K. \\ E-mail: alexandra_loiselet@aviva.com
}

This paper addresses the reforms of the U.K. private pensions system.

The Geneva Papers (2005) 30, 88-91. doi:10.1057/palgrave.gpp.2510011

Keywords: pension reform; United Kingdom

\section{Background}

Until very recently, the U.K. was widely regarded as having a private sector pensions model - built on employer-sponsored final salary-based schemes - that was the envy of many. Today, the talk is of "pensions crises" and "savings gaps", with the final salary promise having to be underpinned by a proposed compensation scheme paid for by other schemes, and an increasing divergence between private sector and public sector employees whose benefits have been immune from challenge and are guaranteed by the government.

While recent equity performance has been common across countries, many of the contributing factors to the current position are U.K. specific. This paper summarizes them, the impact of current or proposed initiatives and the role for insurers.

\section{Decline of the final salary scheme}

A number of factors have contributed to the closing or winding up of schemes. They have become much more expensive through improvements in life expectancy and other increases in the cost of scheme liabilities. This increase in scheme liabilities contrasts with recent investment performance, with many schemes being in significant shortfall on various statutory valuation bases. Those schemes that have wound up recently with insufficient assets have been unable to secure benefits in full and have attracted a great deal of public attention.

Investment decisions for schemes in this environment can be challenging. They are required to reconcile the need to match pension liabilities closely, while maximizing longer term returns for the fund in the interests of members and sponsoring employers.

\section{Money purchase benefits and product pricing}

Although properly funded money purchase schemes and products can compare favourably with final salary benefits, the investment and annuity purchase risk is transferred to the investor. As a result, these schemes are less attractive to the 
employee, although many employers have closed fund salary arrangements in favour of money purchase schemes to reduce the shareholders' exposure to financial risk. There have been no significant inroads into the lower-to-mid-earning segment of savers, which includes those savers who are most likely to be under-provisioned as far as coverage of pensions is concerned.

The introduction of stakeholder pensions in 2001, with a statutory charge cap of 1 per cent of funds and a requirement for employers to "designate" a scheme, was intended to help change this situation. The economics of distributing and securing sufficient return on capital, however, have meant that these stakeholders have not been a worthwhile product for providers to sell, except those at relatively large monthly contributions. There has, therefore, been an effective withdrawal from the market by providers and advisors. The U.K. government is currently reviewing the permitted charging structure of stakeholder products.

\section{Role of the state}

The U.K. state pension consists of a basic flat rate pension plus a means tested Pensions Credit Guarantee. A savings credit has recently been established to mitigate, to a limited extent, the impact of private provision or savings on the value of the Pensions Credit. The government's stated objective has been that, in the long term, two-thirds of state-related benefits would be means tested.

From a market perspective, this objective is likely to undermine incentives to save privately and create confusion about the best course of action for individuals. A growing consensus is emerging that a combination of a low basic state pension and means testing is damaging the savings industry and leading to low pensions take-up. Credible proposals are now being put forward by other political parties and industry figures to increase significantly the basic pension, but to remove any means tested elements.

A Pensions Commission is also currently considering whether there should be some form of compulsion around private provision. While a recommendation is not expected until 2006 (and any implementation would be politically contentious), pensions compulsion could have profound and wide-ranging implications for the sector. Depending on its form, these could include permitted charging structures, minimum contribution levels, the means of distribution and regulation of providers.

\section{Role of the individual}

Recent Association of British Insurers (ABI) research suggests that eight million people, or 38 per cent of the working population, are not currently saving in pensions. A further two million are making insufficient savings. Nearly half of those not saving are not making any alternative provision for their retirement. The same research, paradoxically, suggests that the majority of people accept the need to take responsibility for their retirement either by saving more, or working longer, or a combination of both.

There are many reasons for this gap including lack of access to advice, low employer sponsorship and the whole complexity of - and interaction between - state and private provision. Arguably, pensions tax incentives are not sufficiently attractive on their 
own to encourage low-to-middle earners (many of whom have had recent poor experience with mortgage savings products) to save. The ABI research also demonstrates a widely held belief that property is the best form of investment and is a means of funding retirement income. The latter is evidenced by recent strong growth in equity release products.

Current government policy is not to offer further incentives but, instead, to create greater visibility and information around pensions through the workplace and by introducing benefit statements which combine individual with state entitlements. The Financial Services Authority (the U.K. regulator) and the U.K. government are also considering introducing a lighter touch sales regime for the sale of stakeholder products. In reality, however, many people need to be either pushed or pulled into pensions savings through incentives and/or advice. Currently, there is a shortfall on both.

\section{Pensions simplification and other regulatory change}

The main legislative focus is to restore confidence in defined benefit schemes and to simplify the existing tax structures for pension accumulation and benefits. The legislation proposes a compensation scheme for funds that are wound up in shortfall. This will probably come into effect next year but is unlikely to stem the decline of final salary schemes.

The simplification proposals are welcome and introduce the concepts of favourable tax treatment on a lifetime allowance of $£ 1.5 \mathrm{~m}$ worth of accumulated pension benefits, a $£ 215,000$ annual allowance of maximum contributions for tax relief purposes and up to 25 percent of pension benefits available as tax-free cash. The taxfree cash element should benefit many. These proposals will be implemented in 2006 and, although there will be some who may be disadvantaged, they should provide greater simplicity and clarity around savings requirements - even if they fall short of directly encouraging people to save more.

\section{Threats and opportunities for insurers}

The U.K. demography and savings gap should provide many opportunities for insurers in the medium and longer term. The proposed simplification changes still require annuity products to be purchased and these can only be provided by insurers who have also begun to diversify into alternative retirement funding products, such as equity release. Insurers also have the brand and distribution reach to be well placed over time.

Providers are very actively engaged with government and regulators on key issues, although disagreements remain over product pricing in particular. Other challenges for the savings industry more generally relate to restoring confidence in investments and developing an investment proposition that is seen to be valuable in a low inflation/ returns environment. Impending prudential and accounting changes may well also impact the dynamics and attractiveness of some product types from both providers' and consumers' perspectives. 


\section{About the author}

Richard Harvey became group chief executive of Aviva in April 2001, having been appointed to the board as deputy group chief executive in May 2000. He became from July 2003 non-executive chairman of Norwich Union Life, Aviva's long-term savings business in the U.K. He joined Norwich Union in 1992, holding senior positions in New Zealand and the U.K. before joining the Norwich Union board in 1995 and becoming group chief executive of Norwich Union in 1998. 